\title{
Repeticiones palindrómicas cortas
}

\section{Clustered regulary interspaced short Palindromic repeats}

\author{
Roberto Orofino ${ }^{1}$
}

\section{Edición genética}

E n 1953 los químicos Stanley Miller y Harold Clayton Urey llevaron a cabo un experimento por el cual probaron una revolucionaria idea propuesta por los bioquímicos Oparin y Haldane en la década de 1920. Comprobaron así, que sometiendo mezclas de gases de compuestos inorgánicos a variaciones de temperatura, humedad, descargas eléctricas y radiación ultravioleta, se generan pequeños compuestos orgánicos. Estos, en solución, reaccionan y forman moléculas predecesoras de azúcares, aminoácidos, purinas y pirimidinas. Estas últimas, componentes estructurales de los ácidos nucleicos[1].

Las observaciones sobre el comportamiento bioquímico de los nucleótidos demostraron que los mismos se comportan como sistemas autoreplicantes[2].

En solución, los polinucleótidos pueden dirigir su propia síntesis usándose a sí mismos como moldes estructurales en el ensamblado de hebras complemetarias. Las hebras de ARN tienen la capacidad de plegarse formando estructuras tridimensionales que funcionan como catalizadores enzimáticos acelerando su propio autoensamblado[3].

Cuatro mil millones de años de selección natural acumularon pequeñas ventajas a los polinucleótidos. Se produjo la asociación a membranas, la generación de la célula, el desarollo de la síntesis de proteínas hasta los últimos productos de la optimización evolutiva: sistemas nerviosos dotados de memoria y lenguaje[4].

\section{¿Qué es CRISPR/Cas?}

Siguiendo esta cronología, la vida puede interpretarse como una competencia termodinámica por el aprovechamiento de la energía para conservar y replicar una estructura. Una guerra, donde triunfa el más eficiente. CRISPR/Cas se trata de un herramienta de defensa primitiva, utilizada por bacterias y arqueas. La misma funciona como un sistema de inmunidad adaptativa, para neutralizar material genético extraño introducido por virus o plásmidos[5].

CRISPR/Cas es una nueva poderosa herramienta que permite realizar edición genética in vivo de forma muy eficiente. Su descubrimiento y aplicación, representa un punto de inflexión en el campo de la bioingeniería.

Las siglas CRISPR/Cas provienen de "Clustered Regulary Interspaced Short Palindromic Repeats", o "Repeticiones Palindrómicas Cortas Regularmente Interespaciadas". Cas, es el acrónimo de "CRISPR Associated System", un conjunto de proteínas, en su mayor parte nucleasas. Estas, son enzimas que hidrolizan los enlaces fosfodiéster de las cadenas de ácidos nucleicos, generando el corte o clivaje de las hebras. Existen varios complejos Cas, actualmente el más usado es Cas9 que consiste en una endonucleasa perteneciente a Streptococo pyogenes.

\section{¿Cómo funciona y cuáles son sus potenciales aplicaciones?}

El sistema CRISPR/Cas consiste en secuencias re-

Médico anestesiólogo, Mar del Plata Argentina.

Fecha de recepción: 15 de mayo de 2018

Fecha de aceptación: 23 de julio de 2018

\section{ORCID}

https://orcid.org/0000-0003-4380-9400

Email: roberto.orofino@gmail.com 
petidas de ADN espaciadas regularmente dentro del genoma bacteriano que junto con los genes Cas codifican para proteínas y ARN mensajero capaces de reconocer las secuencias foráneas y clivarlas.

Los loci CRISPR se encuentran en el genoma de bacterias y arqueas y consisten en varias repeticiones conservadas separadas por secuencias espaciadoras de distinta longitud. Estos espaciadores pertenecen a segmentos de ADN de virus o plásmidos. Las secuencias repetidas son en su mayor parte palindrómicas, esto implica que sus transcriptos son complementarios y pueden así generar estructuras de horquillas. Estas interactúan con las proteínas Cas formando un complejo, que será encargado de reconocer material genético exógeno, marcarlo y degradarlo. Los complejos Cas tienen, además, la capacidad de tomar pequeñas partes del material genético extraño, modificarlo e integrarlo dentro del conjunto de secuencias CRISPR. De esta manera el organismo y su descendencia serán capaces de inactivar de forma más eficiente al material genético exógeno en futuras exposiciones.

El sistema CRISPR/Cas se utiliza como una herramienta de edición programable que permite inactivar genes, generar inserciones, deleciones, sustituciones y marcado de secuencias con el objetivo de identificar su posicionamiento. Ofrece grandes aplicaciones en células eucariotas.

Para alcanzar el éxito en la aplicación de una nueva tecnología, es necesario superar algunas barreras: generar un proceso reproducible a un costo y eficiencia razonable.

Existen técnicas de edición anteriores a CRISPR/ Cas: ZFN (Nucleasas tipo de Dedos de Zinc) y TALEN (Nucleasas Efectoras Activadoras de la Transcripción). Las mismas son limitadas porque consisten en la utilización de nucleasas creadas artificialmente para cortar en sitios específicos de las hebras de ADN. Estas enzimas deben diseñarse específicamente para cada sitio de corte, resultando en la edición genética un asunto engorroso, caro y de bajo rendimiento[6],[7].

\section{La edición genética con CRISPR/Cas9 incluye dos etapas[8]}

Primero, un ARN guía se asocia con el complejo Cas9. Este ARN guía es específico de una secuencia concreta del ADN que interesa editar. Cas9 asociada a esta secuencia se hibridará por complementariedad de bases y cortará el ADN mediante su actividad endonucleasa.

Luego, se activan mecanismos intracelulares de reparación de ADN. Existen dos posibles rutas de reparación que pueden gatillarse. La primera es la "recombinación homóloga", consiste en un sistema de unión de segmentos de ADN que se caracteriza por utilizar un molde de nucleótidos para sintetizar el sector faltante y regenerar el empalme de las hebras. Es un sistema muy preciso y puede manipularse para integrar en el sitio de corte una secuencia específica de ADN modificando la secuencia de nucleótidos utilizada como molde. La otra ruta consiste en la "recombinación no homóloga", otro mecanismo de ligadura de hebras más simple y que se caracteriza por ser suceptible a errores, esto produce una reparación imprecisa resultando en un nuevo marco de lectura y la consecuente pérdida de función original del segmento cortado.

\section{CRISPR/Cas9 permite}

Generar un "knock out" o silenciamiento de un gen de interés.

Generar un "knock in" o inserción de una secuencia específica mediante recombinación homóloga. La secuencia insertada puede ser un gen que codifique una proteína particular; un gen promotor que aumente la expresión de esa secuencia; o un gen reportero. Estos últimos codifican proteínas luminiscentes o fluorescentes que permiten localizar la posición de secuencias de interés.

De esta manera, CRISPR puede utilizarse para aumentar o eliminar la expresión de productos, corregir sectores dañados o modificar las secuencias mediante el "copiado y pegado".

CRISPR permite a los investigadores generar modelos celulares y animales de enfermedades de forma rápida y económica.

Una gran aplicación de esta tecnología será corregir los defectos genéticos que subyacen a enfermedades humanas, tumorales, infecciosas y hereditarias. Distrofia muscular de Duchenne, Huntington, fibrosis quística y hemofilia son algunos ejemplos de actuales líneas de investigación en los que CRISPR/Cas9 promete la reparación genética[9].

La modulación de la expresión génica es una manera útil de estudiar las proteínas que podrían ser activadas o inhibidas por drogas en nuevos tratamientos. También se aplicará en estudio de resistencia a fármacos.

El desarollo de nuevas medicaciones es una de las principales inversiones en CRISPR por la industria farmacéutica. El camino es largo y se deben concretar pruebas clínicas, por lo que es incierto saber cuando se dispondrá en el mercado de estas nuevas terapias[10].

Nuevas estrategias son implementadas continuamente al desarrollo de CRISPR. Se han utilizado alter- 
nativas a las enzimas Cas. Una enzima llamada Cpf1, por ejemplo, puede cortar ADN en sitios a los cuales Cas9 no podía unirse. Otras enzimas como Cas13 permiten extender las funciones de CRISPR y editar hebras de ARN[11].

Una estrategia innovadora es la implementación de un sitio de unión a estrógenos al complejo Cas9. Esto permite controlar la actividad del sistema de edición genética a través de señales externas como la variación de la concentración hormonal, permitiendo imitar las sutiles variaciones temporales fisiológicas en modelos de enfermedades[12].

Se ha ensayado la liberación de componentes de CRISPR en sitios específicos como el sistema nervioso central a través del transporte dentro de nanopartículas y su liberación mediante la excitación láser de las mismas[13].

Entre las más recientes novedades puede mencionarse la utilización de CRISPR/Cas9 fuera de la célula, utilizando componentes que le permiten trabajar sin la máquinaria intracelular.

\section{Antecedentes}

Los componentes de CRISPR fueron observados por primera vez en 1987 por científicos Japoneses. En 2005 microbiólogo español Francisco Mojica y su equipo propusieron por primera vez que el sistema formaría parte de un sistema inmunitario bacteriano para la defensa por la infección de virus. ${ }^{\times 2}[14]$. Más tarde, en 2012, las bioquímicas Jennifer Doudna (Estados Unidos) y Emmanuelle Charpentier (Francia) elucidaron los componentes y el mecanismo molecular de funcionamiento de CRISPR/Cas9 y demostraron su potencial uso en procariotas. ${ }^{\times 1}[15]$. El bioquímico Feng Zhang (China) es el primero en utilizarlo en células eucariotas, que, debido a sus complejos mecanismos regulatorios, presentaron históricamente las mayores dificultades para la manipulación genética. ${ }^{\times 3}$ [16].

Sin dudas, alguien recibirá un Nobel por el descubrimiento de CRISPR/Cas. Serán los aspectos que considere la comunidad científica como relevantes desde su primera observación, los que determinen tal asignación. Mientras tanto, existe un interesante trasfondo sobre la propiedad intelectual que se traduce en una despiadada guerra de patentes biotecnológicas.

\section{Sus implicancias}

Más allá de que esta tecnología posee una alta precisión, aún no puede establecerse seguridad la tasa de errores generados. Los mismos se conocen como "actividad off-target"[17]. Continuamente se publican reportes de errores en los resultados de las ediciones genéticas por CRISPR. Los mismos son seguidos de publicaciones evaluando y refutando los estudios que reportan tales errores. Consiste de una disputa científica de ataque y defensa a un sistema con un amplio abanico de intereses de fondo[18],[19],[20],[21].

Otro problema a destacar, es el potencial uso irresponsable de la edición genética. Como ejemplo, puede citarse la controversial utilización de un tratamiento no aprobado para eliminar el virus herpes simplex por el director de una empresa biotecnológica, Aaron Traywick. El mismo se autoinyectó una vacuna con un tratamiento CRISPR durante una conferencia transmitida en vivo en febrero de 2018, resultando ser en teoría, el primer humano de la historia en autoeditar su ADN.

Esta novedosa herramienta representa un punto de inflexión en la historia de la humanidad. El hombre es capaz de editar el genoma de forma simple, eficiente y con menor costo que técnicas predecesoras. Las aplicaciones son inmensas, y sus consecuencias inciertas. Representa el principio de nuevos abordajes éticos sobre el uso de la tecnología. ¿Hasta donde es peligroso beneficiarnos de la manipulación genética de animales y plantas? ¿Cómo podrá regularse? ¿Que riesgos representa esta tecnología en manos equivocadas?

La humanidad enfrentará en breve grandes dilemas sobre el libre acceso al conocimiento científico. ¿Como se controlará el potencial bioterrorismo? La edición genética y la infectología podrían representar un problema mayor, los ataques podrían implicar lentas derivas genéticas artificiales a través de generaciones o abruptos knockouts enzimáticos con resultados devastadores.

La velocidad del progreso científico puede objetivarse teniendo en cuenta que James Watson, uno de los descubridores de la estructura cristalográfica del ADN, está vivo hoy. En menos de una generación el hombre describió la estructura de los ácidos nucleicos, su función y aprendió a manipularlos.

¿Podría esto representar una explicación a la paradoja del físico italiano Enrico Fermi? ¿Será ésta la causa del aparente silencio captado por nuestros radiotelescopios desde el espacio profundo? ¿Sucederá que, la historia natural de la inteligencia implique el rápido aprendizaje de la manipulación genética, generando disbalances artificiales y la autodestrucción de sí misma?

El tiempo aclarará el misterio. Aunque parece claro que, la realidad, es la mejor historia de ciencia ficción.

CRISPR/Cas, nueva revolución en tecnología. Otro 
paso adelante o ... el principio del fin?

\section{Multimedia}

https://www.youtube.com/watch?v=2pp17E4E-O8 (animación explicativa)

h t t p s: // w w w. youtube.com/ watch? $v=4 Y K F w 2 K Z A 50 \& t=100$ s (Animación Explicativa)

https://www.youtube.com/watch?v=w2_JN1 JntlU (CRISPR/Cas9 observado desde microscopio de fuerza iónica)

https://www.youtube.com/watch? v=GR jWexoA_Y\&t=1466s (Conferencia de Aaron Traywick -minuto 23:00 administrándose CRISPR/Cas9).

\section{Referencias}

1. Miller, Stanley L, y Harold C. Urey. Organic Compound Synthesis on the Primitive Earth. Science 130, n.o 3370 (1959): 245-51.

2. Orgel, Leslie E. Molecular replication». Nature 358 (16 de julio de 1992): 203.

3. Bartel, DP, y JW Szostak. Isolation of new ribozymes from a large pool of random sequences [see comment]. Science 261, n.o 5127.

4. Cavalier-Smith, T. The Origin of Cells: A Symbiosis between Genes, Catalysts, and Membranes. Cold Spring Harbor Symposia on Quantitative Biology 52 (1 de enero de 1987): 805-24.

5. Sampson TR, Weiss DS. CRISPRCas systems: new players in gene regulation and bacterial physiology. Front Cell Infect Microbiol. 2014 Apr;4:37.

6. Taheri-Ghahfarokhi A, MalaverOrtega LF, Sumer H. Genome Modification of Pluripotent Cells by Using Transcription ActivatorLike Effector Nucleases (TALENs). En Cell Reprogramming: Methods and Protocols, editado por Paul J. Verma y Huseyin Sumer, 253-67.

7. Gupta A, Christensen RG, Rayla $A L$, Lakshmanan A, Stormo GD, Wolfe SA. An optimized twofinger archive for ZFN-mediated gene targeting. Nat Methods. 2012 Jun;9(6):588-90.
8. Ran, F Ann, Patrick D Hsu, Jason Wright, Vineeta Agarwala, David A Scott, y Feng Zhang. Genome engineering using the CRISPRCas9 system. Nature Protocols 8 (24 de octubre de 2013): 2281.

9. Cai L, Fisher AL, Huang $H$, Xie $Z$. CRISPR-Mediated Genome Editing and Human Diseases. Genes Dis. 2016 Dec;3(4):244-51.

10. Fellmann C, Gowen BG, Lin PC, Doudna JA, Corn JE. Cornerstones of CRISPR-Cas in drug discovery and therapy. Nat Rev Drug Discov. 2017 Feb;16(2):89-100.

11. Cox DB, Gootenberg JS, Abudayyeh OO, Franklin B, Kellner MJ, Joung J, et al. RNA editing with CRISPR-Cas13. Science. 2017 Nov;358(6366):1019-27.

12. Lu J, Zhao C, Zhao Y, Zhang J, Zhang $Y$, Chen L, et al. Multimode drug inducible CRISPR/ Cas9 devices for transcriptional activation and genome editing. Nucleic Acids Res. 2018 Mar;46(5):e25-25.

13. Lee B, Lee K, Panda S, GonzalesRojas R, Chong A, Bugay V, et al. Nanoparticle Delivery of CRISPR into the Brain Rescues a Mouse Model of Fragile X Syndrome from Exaggerated Repetitive Behaviours. Nat Biomed Eng. 2018 Jul;2(7):497-507.

14. Mojica F, Díez-Villaseñor $C$, García-Martínez J, Soria E. Intervening Sequences of Regularly Spaced Prokaryotic Repeats Derive from Foreign Genetic Elements. 2005;60:
15. Jinek $M$, Chylinski $K$, Fonfara I, Hauer M, Doudna JA, Charpentier E. A programmable dual-RNA-guided DNA endonuclease in adaptive bacterial immunity. Science. 2012 Aug;337(6096):816-21.

16. Cong, Le, F. Ann Ran, David Cox, Shuailiang Lin, Robert Barretto, Naomi Habib, Patrick D. $\mathrm{Hsu}$, et al. Multiplex Genome Engineering Using CRISPR/Cas Systems. Science 339, no. 6121 (February 15, 2013): 819.

17. Zhang $X H$, Tee $L Y$, Wang $X G$, Huang QS, Yang SH. Off-target Effects in CRISPR/Cas9-mediated Genome Engineering. Mol Ther Nucleic Acids. 2015 Nov;4:e264.

18. Anderson KR, Haeussler M, Watanabe $C$, Janakiraman $V$, Lund J, Modrusan Z, et al. CRISPR off-target analysis in genetically engineered rats and mice. Nat Methods. 2018 Jul;15(7):512-4.

19. Schaefer KA, Wu WH, Colgan DF, Tsang SH, Bassuk AG, Mahajan VB. Unexpected mutations after CRISPR-Cas9 editing in vivo. Nat Methods. 2017 May;14(6):547-8.

20. Schaefer KA, Wu WH, Colgan DF, Tsang SH, Bassuk AG, Mahajan VB. Retraction: unexpected mutations after CRISPR-Cas9 editing in Vivo. Nat Methods. 2018 Apr;15(5):394.

21. CRISPR Off-Targets: Reassessment A. CRISPR off-targets: a reassessment. Nat Methods. 2018 Mar;15(4):229.30. 